\title{
COMPORTAMENTO DE GENÓTIPOS DE FEIJÃO COMUM (Phaseolus vulgaris L.) NAS CONDIÇÕES DE UM MUNICÍPIO NO NORDESTE BRASILEIRO
}

\author{
Rosieudo LEITE DA SILVA ${ }^{1}$; Francisco de Assis da SILVA ${ }^{2}$; Carlos Alberto ISAZA ${ }^{3}$; Ana \\ Carolina Assis SAMPAIO ${ }^{4}$
}

\author{
${ }^{1}$ Graduação em Engenharia Agronômica/Universidade Federal da Paraíba (UFPB). E-mail: \\ agroecologia65@gmail.com \\ ${ }^{2}$ Bacharel em Ecologia/UFPB; Mestre em Desenvolvimento e Meio Ambiente (PRODEMA)/UFPB. E-mail: \\ assismandela@gmail.com \\ ${ }^{3}$ Graduação em Contaduría Pública/Universidad del Valle (UNIVALLE/Colômbia); Mestrando em \\ Desenvolvimento e Meio Ambiente (PRODEMA)/UFPB. E-mail: carlos0isaza@ gmail.com \\ ${ }^{4}$ Graduanda em Administração/ UFPB. E-mail: anacassissampaio@gmail
}

Resumo. O cultivo do feijoeiro comum é de grande importância no contexto socioeconômico nacional, devido ao seu cultivo ser realizado por pequenos e grandes produtores, em diversificados sistemas de produção e em todas as regiões brasileiras. No Brasil, o feijoeiro comum é submetido a diferentes condições ambientais, pois ele é cultivado em vários estados, em diferentes épocas de semeadura. A identificação de cultivares, com maior estabilidade fenotípica, tem sido uma alternativa muito utilizada para atenuar os efeitos da interação genótipos com ambientes. Sendo assim, objetivouse com este trabalho, avaliar o desempenho de caracteres de produtividade agronômico de quinze genótipos de feijão comum no município de Areia-PB. O experimento foi conduzido no setor de olericultura do CCA-UFPB. Foi utilizado o delineamento em blocos casualizado com quinze tratamentos correspondentes aos diferentes genótipos de feijão comum com 4 repetições. Foram avaliados onze caracteres: NVP, MFVG, CV, DV, NGV, MFCG, MSCG, FC, PG, PP e RG. Os resultados obtidos foram submetidos à análise de variância com os quadrados médios comparados pelo teste de médias. Apenas o genótipo G2 apresentou tendência aos menores valores na variável número de vagens. planta $^{-1}$; verificou-se ainda que não houve diferença significativa para o rendimento de grãos nos genótipos estudados.

Palavras-chave: Feijão de arranca; Soberania alimentar; Leguminosas.

\section{BEHAVIOR OF COMMON BEAN GENOTYPES IN (Phaseolus vulgaris L.) IN THE CONDITIONS OF A MUNICIPALITY FROM THE BRAZILIAN NORTHEAST}

Abstract. The beans plant culture is very significance in socioeconomic Brazilian context. Small and large farmers perform the planting of this cereal in diversified production systems and in all country regions, submitting its production to variations in environmental conditions and different sowing dates. The identification of cultivars with largest phenotypic stability is been used to mitigate the 
effects of genotype with environment interaction. Therefore, the objective of this study was to evaluate the performance of agronomic productivity characteristics of the fifteen genotypes of common bean in Areia-PB. Experiments conducted in the horticulture sector CCA-UFPB. It applied the method of randomized block design with fifteen treatments covering the various genotypes of common bean in four replications. Eleven characters appraised NVP, MFVG, CV, DV, NGV, MFCG, MSCG, FC, PG, PP and RG. Obtained results analyzed by the variance with mean squares comparing the mean test. Just genotype $\mathrm{G} 2$ tended to lower value in the variable number of vagens.plant ${ }^{-1}$, It was also found that no significant difference to grain yield in genotypes. The results were submitted to analysis of variance with mean squares compared the mean test. Only the G2 genotype tended to lower value in the variable number of vagens.plant ${ }^{-1}$. It also found that there was no significant difference for grain yield in genotypes.

Keywords: String beans; Food sovereignty; Legumes.

\section{COMPORTAMIENTO DE LOS GENOTIPOS DE FRIJOL COMÚN (Phaseolus vulgaris L.) EN LAS CONDICIONES DE UN MUNICIPIO EN EL NORDESTE BRASILEÑO}

Resumen. El cultivo del fríjol común es de gran importancia en el contexto socioeconómico nacional, debido a que su cultivo es realizado por pequeños y grandes productores, en diversificados sistemas de producción y en todas las regiones brasileñas. En Brasil, el fríjol común es sometido a diferentes condiciones ambientales, pues es cultivado en varios estados, en diferentes épocas de siembra. La identificación de cultivos, con mayor estabilidad fenotípica, ha sido una alternativa bastante utilizada para atenuar los efectos de la interacción de genotipos con ambientes. Siendo así, se objetivó con este trabajo, evaluar el desempeño de caracteres de productividad agronómica de quince genotipos de frijol común en el municipio de Areia-PB. El experimento fue conducido en el sector de horticultura del CCA-UFPB. Fue utilizado el delineamiento en bloques casualizado con quince tratamientos correspondientes a los diferentes tipos genotipos de frijol común con 4 repeticiones. Fueron evaluados once caracteres: NVP, MFVG, CV, DV, NGV, MFCG, MSCG, FC, PG, PP e RG. Los resultados obtenidos fueron sometidos al análisis de variación con lo cuadrados medios comprados por el test de medias. Apenas el genotipo G2 presentó tendencia a los menores valores en la variable número de vainas planta ${ }^{-1}$; se verificó si todavía que no hubo diferencia significativa para el rendimiento de granos en los genotipos estudiados.

Palabras clave: Frijol de arranca; Soberanía alimentar; Leguminosas.

\section{INTRODUÇÃO}

Os problemas relacionados com a segurança dos alimentos são cada dia mais frequentes e decorrentes da urbanização intensa, da globalização do mercado de alimentos, de mudanças 
nos hábitos de consumo e das técnicas de produção primária cada dia mais intensificadas, entre outros fatores. Em decorrência disto, a segurança dos alimentos tem se tornado uma grande preocupação para a sociedade e um desafio, tanto para os países desenvolvidos como para os países em desenvolvimento (NEVES, 2006).

A agricultura sustentável, produtiva e ambientalmente equilibrada apoia-se em práticas conservacionistas de preparo do solo, rotações de culturas e consórcios, no uso da adubação verde e de controle biológico de pragas, bem como no emprego eficiente dos recursos naturais. Infere-se daí que os processos biológicos que ocorrem no sistema solo/planta, efetivados por microrganismos e pequenos invertebrados, constituem a base sobre a qual a agricultura agroecológica se sustenta (ASSIS, 2005).

A promoção dos pequenos produtores de alimentos promove a equidade e a inclusão social em simultâneo a uma maior e mais diversificada oferta de alimentos à população produzidos sob formas sustentáveis (MALUF, 2004). Dentre as diversas culturas produzidas pelos pequenos produtores destaca-se nacionalmente a cultura do feijão comum.

O feijoeiro é a cultura anual mais plantada no Brasil, sendo o cereal mais consumido em seu território, apresenta uma vasta amplitude de genótipos, dividindo-se basicamente em duas espécies vegetais, a Vigna unguiculata, representada pelo feijão caupi ou feijão-decorda, e o Phaseolus vulgaris, representado pelo feijão carioquinha ou mulatinho (TORRES et al., 2008; MASTRANTONIO; PORTO; GOMES, 2007), também denominado de feijão comum.

De acordo com Ribeiro et al. (2008), o feijão comum é um vegetal que é cultivado em diversas regiões, podendo-se inferir que em alguns locais apresenta condições de produzir feijão praticamente o ano todo; essas condições baseiam-se na precipitação e temperatura média, necessárias ao feijoeiro, sem ocorrência de excesso de chuva e calor, bem como da escassez de água e temperaturas muito baixas.

As variações observadas na preferência dos consumidores orientam a pesquisa tecnológica e direcionam a produção e comercialização do produto, pois as regiões brasileiras são bem definidas quanto à preferência do grão de feijoeiro comum consumido; algumas características como a cor, o tamanho e o brilho do grão, podem determinar o seu consumo, enquanto a cor do halo pode também influenciar na comercialização (EMBRAPA, 2003).

O cultivo do feijoeiro comum é de grande importância no contexto socioeconômico nacional (CABRAL et al., 2011), devido ao seucultivo ser realizado por pequenos e grandes produtores, em diversificados sistemas de produção e em todas as regiões brasileiras (EMBRAPA, 2003). Sendo o Brasil destaque no cenário internacional como o maior produtor 
e consumidor de feijão, sendo a produtividade média considerada baixa, principalmente pelo fato do pequeno uso de sementes certificadas e pelo manejo inadequado da cultura (CABRAL et al., 2011).

Os órgãos de pesquisa têm colaborado grandemente com a disponibilização de cultivares de alto rendimento e de maior eficiência na utilização de insumos, melhorando os índices de produtividade e, conseqüentemente, de renda do produtor;contudo, o aumento da taxa de uso de sementes melhoradas, bem como a ocorrência de estiagens e o simples abandono de cultivo, têm colaborado para o desaparecimento de cultivares conhecidas como crioulas;estas cultivares são caracterizadas pelo cultivo em uma determinada região, por várias gerações, o que aumenta a probabilidade de que os mecanismos de seleção natural atuem, onde os indivíduos de maior potencial adaptativo são perpetuados (SILVEIRA et al., 2007).

Apesar da grande importância do feijão comum como alimento da base alimentar do povo brasileiro, e por ser a principal fonte protéica das pessoas de menor poder aquisitivo, este tem como sua base produtiva a pequena propriedade rural, onde seu cultivo é predominantemente em cultivo solteiro (TEIXEIRA et al., 2011). O estudo de características morfológicas e agronômicas das plantas cultivadas é importante para se conhecer a divergência genética do conjunto de germoplasma disponível para fins de utilização em programa de melhoramento genético (ELIAS et al., 2007).

\section{Agricultura familiar}

O segmento da agricultura familiar, internamente, apresenta-se bastante diversificado nas várias estruturas agrárias e muitos estudos continuam a ser produzidos visando aprofundar o conhecimento acerca da produção familiar na agricultura, entretanto, o que se deve levar em consideração, é que este segmento se reproduz de maneiras tão diversas, que se faz necessário uma análise específica em cada espaço, situação e tempo, devido à diversidade de estratégias que o agricultor encontra para permanecer no campo (FINATTO; SALAMONI, 2008).

A família é o fundamento dessa sociedade rural: famílias se reúnem em comunidades, que articulam parentesco, ambiente, espaço e história para formar unidades de reprodução de cultura e técnica material, de trocas de bens e dons; famílias e comunidade são depositárias de um histórico de convívio, aprendizado e experimentação que forma um acervo respeitável de conhecimentos sobre o meio (RIBEIRO et al., 2008).

Nesse sentido, uma constatação merece destaque, é inegável que o segmento da agricultura familiar se desenvolve e persiste até hoje, ficando evidenciado na significativa 
quantidade de mão-de-obra relativa à família empregada no campo e à diversidade (em quantidade e qualidade) de produtos oferecidos, por este segmento, para atender as demandas do mercado consumidor interno e mesmo o externo, por isso, os agricultores familiares, são considerados essenciais para a produção de alimentos tanto da população rural quanto urbana (FINATTO; SALAMONI, 2008).

Para Macêdo e Candido (2011) muitas discussões acerca de formas alternativas de desenvolvimento passam a ser consolidadas em função do quadro atual de escassez de recursos e instabilidade social e econômica, onde estas sejam capazes de modificar o quadro de desigualdades entre povos e regiões, a partir das relações locais de desenvolvimento e gestão, em que os cidadãos podem articular-se de maneira criativa e diferenciada nas diversas territorialidades e nas quais as pessoas possam participar diretamente deste processo, uma vez que conhecem melhor a realidade e a escala de decisão que coincide com o seu horizonte de conhecimento.

O meio rural do Nordeste do Brasil apresenta inúmeras características que o distingue, desfavoravelmente, das demais sub-regiões em termos de desenvolvimento social, entre elas, dificilmente se pode apontar uma de mais fácil identificação, de maior representatividade desse atraso e de maior poder de constrangimento em relação a avanços sociais futuros que os baixos níveis de escolaridade da população (MELO; DUARTE, 2010).

As duas últimas décadas testemunharam a emergência do discurso da sustentabilidade como a expressão dominante no debate que envolve as questões de meio ambiente e de desenvolvimento social em sentido amplo; em pouco tempo, sustentabilidade tornou-se palavra mágica, pronunciada indistintamente por diferentes sujeitos, nos mais diversos contextos sociais e assumindo múltiplos sentidos (LIMA, 2003).

A educação influencia de várias formas a qualidade de vida das pessoas, ela não só afeta positivamente o nível de produtividade e renda do trabalho, como também uma população mais educada torna-se capaz de participar de forma mais ativa na vida social e política do País (NEY; HOFFMANN, 2009).

\section{Feijão comum}

O feijoeiro comum (Phaseolus vulgaris L.) é uma cultura de grande importância no Brasil, sendo cultivado em grande parte do território nacional e em quase todos os estados (PEREIRA et al., 2009). Coloca-se como a terceira cultura em área plantada, atingindo 9\% da área cultivada (BARROSO; YAMAUTI; ALVES, 2010).

O País destaca-se na produção e no consumo mundial de feijão comum sendo essa 
fabácea a principal fonte de proteína vegetal de consumo direto (GONÇALVES et al., 2010), possuindo um teor protéico de aproximadamente $22 \%$, este alimento é, juntamente com o arroz, consumido por milhões de brasileiros, constituindo-se a base alimentar do País (SALGADO et al., 2007).

Diante dos avanços tecnológicos e das características socioeconômicas, o cultivo do feijoeiro vem sendo praticado, nos dias atuais, por produtores rurais que dispõem dos mais variados níveis de tecnologia, sendo dos mais simples aos mais avançados (LOPES et al., 2011), desde a agricultura familiar, com escasso ou sem nenhum uso de tecnologia, até o grande empresário agrícola, com utilização da mais moderna tecnologia de produção (MELO et al., 2007). Por este motivo, a cultura é submetida às mais variadas condições tecnológicas (PEREIRA et al., 2009).

Tabela 1. Rendimento médio da produtividade do feijão comum em kg.ha ${ }^{-1}$, entre os anos de 2008 a 2011.

\begin{tabular}{lcccc}
\hline \multicolumn{1}{c}{ Localidades } & \multicolumn{4}{c}{ Ano } \\
\cline { 2 - 5 } & 2008 & 2009 & 2010 & 2011 \\
\hline Brasil & 915 & 850 & 922 & 935 \\
Nordeste & 476 & 391 & 357 & 427 \\
Paraíba & 397 & 269 & 136 & 234 \\
Sertão Paraibano - PB & 273 & 210 & 86 & 240 \\
Borborema - PB & 289 & 303 & 127 & 177 \\
Agreste Paraibano - PB & 581 & 303 & 173 & 249 \\
Mata Paraibana - PB & 454 & 402 & 244 & 354 \\
\hline
\end{tabular}

Fonte: SIDRA-IBGE, 2019.

Seu cultivo constitui uma das principais explorações agrícolas, preferencialmente por parte dos pequenos produtores rurais, principalmente dentro da agricultura familiar (LOPES et al., 2011), constituindo uma alternativa para exploração agrícola em pequenas propriedades, com ocupação de mão-de-obra menos qualificada (SOUZA et al., 2011).

No Brasil, o feijoeirocomum é submetido a diferentes condições ambientais, pois ele é cultivado em vários estados, em diferentes épocas de semeadura (águas, seca e inverno) e sistemas de cultivo, que variam desde a agricultura de subsistência, com baixo uso de insumos, até a agricultura empresarial, de alta tecnologia (PEREIRA et al., 2010b).

Ainda sob diferentes sistemas de cultivo como solteiro e consorciado, nas mais variadas condições edafoclimáticas, e por ser de ciclo curto torna-se bastante sensível à 
competição por diversas espécies de plantas daninhas, sobretudo nos estádios iniciais de desenvolvimento vegetativo (SCHOLTEN; PARREIRA; ALVES, 2011). Teixeira et al. (2009) relata que sua baixa capacidade competitiva se enquadrado no grupo de culturas que menos sombreiam o solo, sofre intensa interferência das plantas daninhas, resultando em sérios prejuízos no crescimento, na produtividade e na operacionalização de colheita.

A identificação de cultivares, com maior estabilidade fenotípica, tem sido uma alternativa muito utilizada para atenuar os efeitos da interação genótipos com ambientes e tornar o processo de indicação de cultivares mais seguro (MELO et al., 2007).

Como o feijoeiro-comum é cultivado em 25 dos 26 estados brasileiros, e vários deles apresentam mais de uma época de semeadura, a indicação de cultivares para todos os estados produtores têm sido dificultada e, como consequência, não existem novas cultivares registradas para vários estados. Uma maneira de atenuar esse problema seria a indicação de cultivares de forma conjunta para as diferentes épocas de semeadura (PEREIRA et al., 2010a).

A obtenção de novas cultivares de feijoeiro-comum mais produtivas, menos sensíveis aos estresses bióticos e abióticos, e com características que atendam ao mercado consumidor, tem-se constituído, ao longo dos anos, em desafio (MELO, et al., 2007). No entanto, tem-se observado sinais de desequilíbrio ambiental e, conseqüentemente, prejuízos à produtividade das culturas, evidenciando a necessidade de reavaliação das práticas agrícolas adotadas, além do conhecimento de estratégias racionais de manejo (CARVALHO et al., 2007).

A ocorrência da interação entre genótipos e ambientes (GxA) tem grande importância, principalmente para o caráter produção de grãos (PEREIRA et al., 2009). Dentre os fatores Pereira et al. (2010b) que afetam a interação genótipos x ambientes nas condições de cultivo do feijoeirocomum, merecem destaque a variação entre anos, entre locais e entre épocas de semeadura.

No entanto, apresenta produtividade baixa, decorrente de problemas associados a doenças de difícil controle, ao alto custo dos pesticidas e à precária situação financeira do pequeno produtor (agricultura familiar), que é responsável por mais de $67 \%$ da produção nacional (GALBIATTI et al., 2011), além de utilizarem pouca tecnologia ou cultivar o feijão consorciado com outras culturas (SALGADO et al., 2007), o que leva diminuição de densidade de plantas.

Salienta-se que os três principais caracteres que compõem o rendimento final na cultura do feijão são: número de vagens por unidade de área, número de grãos por vagem e massa dos grãos; podendo haver efeito compensatório no rendimento de grãos, com a 
diminuição do número de vagens e de grãos por planta de feijão e do aumento da massa dos grãos, em resposta ao aumento da população de plantas por área (ZILIO et al., 2011). Silva et al. (2011) verificando implicações do local de origem das linhagens na magnitude da interação com ambientes, concluíram que tais locais não influenciaram a estabilidade das linhagens quando as suas condições ambientais são semelhantes às do local de cultivo, mas interfere no desempenho das linhagens quando as condições ambientais são muito diferentes.

Avaliando o desenvolvimento da cultura de feijoeiro utilizando biofertilizante e adubação mineral influenciou no crescimento das plantas, na massa seca das folhas, caule, pecíolo, parte aérea e área foliar (GALBIATTI et al., 2011).

Estudando a adaptação de genótipos de feijoeirocomum à deficiência hídrica, verificaram que a produtividade dos genótipos em condições de tal deficiência diminuiu com o aumento da temperatura das folhas e que a cada grau de aumento resultou em $20 \mathrm{~kg} \cdot \mathrm{ha}^{-1} \mathrm{de}$ redução na produtividade dos genótipos (GUIMARÃES et al., 2011). Zilio et al. (2011) verificando caracteres de rendimento para a produção final em genótipos crioulos de feijão comum cultivados em três ambientes, constataram respostas diferenciadas dos genótipos ao ambiente de cultivo.

\section{MATERIAIS E MÉTODOS}

O experimento foi conduzido no Setor de Olericultura do Centro de Ciências Agrárias da Universidade Federal da Paraíba, situado na propriedade Chã de Jardim, a uma latitude de $06^{\circ}$ 58' S, longitude $35^{\circ} 42^{\prime} \mathrm{W}$, e com uma altitude de 534m (GONDIM, 1999), localizado no Brejo Paraibanono município de Areia. De acordo com a classificação de Koeppen, a região apresenta clima As', que se caracteriza como quente e úmido, com chuvas de outono/inverno e período seco entre setembro e fevereiro. O solo é classificado como NEOSSOLO REGOLÍTICO psamítico típico (EMBRAPA, 1999).

\section{Coleta e análise química do solo e esterco bovino}

Antes da instalação do experimento foi realizada uma amostragem e coleta do solo na camada de 0-20 cm da área experimental, assim também como do esterco bovino, ondese colheram em seis pontos bem distribuídos sobre a pilha a fim de perfazer uma amostra composta. Em seguida, as amostras foram encaminhadas para o Laboratório de Química e Fertilidade do Solo do Centro de Ciências Agrárias da Universidade Federal da Paraíba, para realização das análises de química e fertilidade, segundo metodologia da (EMBRAPA, 1997). Cujos dados estão dispostos na Tabela 2. 
Tabela 2. Atributos de químicas e fertilidade das amostras de solo da área experimental e do esterco bovino. CCA-UFPB, Areia, 2013

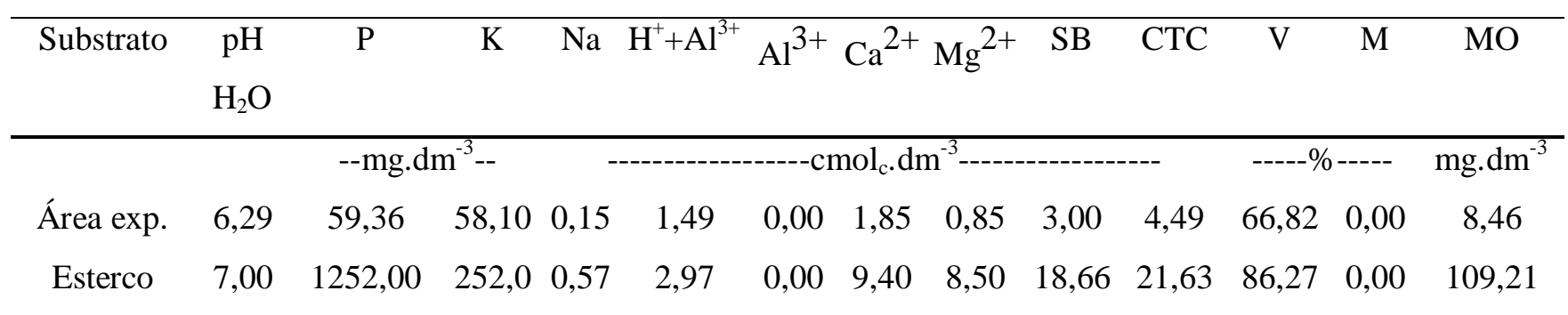

pH $\mathrm{H}_{2} \mathrm{O}$ : potencial de Hidrogênio; P: Fósforo; K: Potássio; MO: Matéria Orgânica; Na: Sódio; $\mathrm{H}^{+}+\mathrm{Al}^{3+}$ :

Hidrogênio + Alumínio; $\mathrm{Al}^{3+}:$ Alumínio; $\mathrm{Ca}^{2+}$ : Cálcio; $\mathrm{Mg}^{2+}$ : Magnésio; SB: Soma de Bases; CTC: Capacidade de Troca Catiônica; V:Saturação por Bases; m: Saturação por Alumínio.

Na Tabela 3, encontram-se os dados mensais referentes à temperaturamáxima, mínima e média em ${ }^{\circ} \mathrm{C}$, umidade relativa do ar em \% e a precipitação pluviométrica em mm.mês ${ }^{-1}$, durante a condução do trabalho.

Tabela 3. Dados climáticos de outubro de 2011 a janeiro de 2012, período de condução do experimento. CCA-UFPB, Areia-PB, 2013

\begin{tabular}{cccccc}
\hline Meses & $\underline{\text { Tmáx }}$ & $\underline{\text { Tmin }}$ & $\underline{\mathrm{Tm}}$ & $\underline{\mathrm{UR}}$ & $\underline{\mathrm{PP}}$ \\
& $---{ }^{-}$ & $\%$ & $\mathrm{~mm}$ \\
\hline Outubro (2011) & 27,6 & 19,2 & 23,4 & 80 & 13,8 \\
Novembro (2011) & 28,2 & 19,7 & 24,0 & 77 & 48,3 \\
Dezembro (2011) & 29,0 & 19,9 & 24,4 & 74 & 29,9 \\
Janeiro (2012) & 27,5 & 19,6 & 23,5 & 85 & 183,3 \\
\hline
\end{tabular}

Fonte: Dados coletados da Estação Meteorológica do CCA/UFPB, Areia-PB, 2013.

Tmáx: temperatura máxima; Tmin: temperatura mínima; Tm: temperatura média; UR: umidade relativa do ar; PP: precipitação pluviométrica.

\section{Condução do experimento}

O preparo do solo foi realizado com enxada manual. A semeadura dos quinze genótipos do feijoeiro comum foi realizada simultaneamente, dentro das covas, sendo manual a distribuição das sementes. A adubação básica foi efetuada, utilizando $10 \mathrm{~m}^{3} \cdot \mathrm{ha}^{-1}$ de esterco bovino aplicando-se na entrelinha das filas de feijão localizada na região central do leirão, sendo que em cada leirão foram conduzido duas filas laterais e opostas.

$\mathrm{Na}$ semeadura foram distribuídas quatro sementes por cova, onde as plantas tiveram 
distribuição linear e espaças a cada $0,30 \mathrm{~m}$, onde 10 dias após emergência foi efetuado o desbaste das plantas, objetivando conservar duas plantas por cova. O manejo de plantas daninhas foi feito por capinas utilizando enxadamanual.

A colheita foi realizada manualmente aos 70 dias após o semeio. Logo após as plantas foram transportadas para piso de alvenaria a fim dereduzir a umidade dos grãos a $4 \%$. A debulha foi feita manualmente, assim como a seleção e limpeza dos grãos com auxilio de peneira.

As sementes foram adquiridas junto a agricultores e o esterco em propriedade circunvizinha. O cultivo foi realizado em sequeiro.

\section{Delineamento experimental e variáveis avaliadas}

Foi utilizado o delineamento em blocos casualizado com 15 tratamentos correspondentes aos diferentes genótipos de feijão comum com 4 repetições. A unidade experimental foi composta por seis filas de 3,0 m de comprimento, espaçada $1,0 \mathrm{~m}$, totalizando uma área de $18,0 \mathrm{~m}^{2}$ por unidade experimental. Em cada cova ficaram 2 plantas definitivas compondo 120 plantasem cada parcela. Foram avaliados onze caracteres, sendo eles:

Número de vagem por planta (NVP): realizada a partir da contagem manual do número de vagens presentes nas plantas avaliadas na área útil, expressos em unidade (MORAES et al., 2011);

Matéria fresca da vagem com grão (MFVG): foram retiradas cinco plantas de cada parcela, onde foram retiradas todas as vagens, em seguida estas foram pesadas em balança digital e dividido pelo número de vagens coletadas, expressos em grama (BENINCASA, 2004);

Comprimento de vagem (CV): foram retiradas 25 vagens por parcelas, onde cada uma destas foram medidas com auxilio de fita métrica, expressos em centímetro;

Diâmetro de vagem (DV): foram retiradas 25 vagens por parcela, onde cada uma destas foram medidas com auxilio de paquímetro digital, expressos em milímetro;

Número de grãos por vagem (NGV): foram retiradas cinco plantas de cada parcela para a determinação número de grãos por vagem, expressos em unidade (CARVALHO et al., 2007); Peso médio da matéria fresco de cem grãos (MFCG) ematéria seca de cem grãos (MSCG): mensuradas oito pesagens de cem sementes, estimadas para 1000 grãos em balança digital em quadruplicata, expresso em gramas (RIGON et al., 2011);

O índice de palha (IP) foi obtido pela formula:

$$
\mathrm{IP}=\frac{\text { (máteria fresca da semente por vagem X 100) }}{\text { máteria fresca da vagem com semente }} \div 100
$$


Sendo esta adimensional;

A produtividade de grãos (PG): Foi determinadaatravés da colheita das plantas presentes na área útil da parcela (duas linhas com $2 \mathrm{~m}$ ), as quais foram trilhadas manualmente e os grãos foram pesados, os dados corrigidos para $13 \%$ de umidade e expressos em kg.ha ${ }^{-1}$ (MORAES et al., 2011).

As perdas de grãos (PP): foi feita a partir da seleção dos grãos inviáveis ao comercio e esboçados em kg.ha ${ }^{-1}$.

O rendimento de grãos (RG): foi obtido pela subtração da PG pela PP e pronunciado em kg.ha ${ }^{-1}$.

\section{Análise estatística}

As variáveis avaliadas foram submetidas à análise de variância, a comparação de médias foi feita pelo teste de Scott-Knott a $1 \%$ de probabilidade. As mesmas foram realizadas com o auxílio do programa computacional Sistema para Análise de Variância - SISVAR (FERREIRA, 2000).

\section{RESULTADOS E DISCUSSÃO}

$\mathrm{Na}$ variável número de vagens.planta ${ }^{-1}$ (NVP) os genótipos não diferiram estatisticamente entre si, no entanto, a média para esta variável foi equivalente a 6,17 vagens.planta ${ }^{-1}$. Efeito bem superior foi encontrado em Rigon et al. (2011) ao conferir valores medial de 13,20 vagens.planta $^{-1}$. Zilio et al. (2011), observaram valores que variaram de 2,5 a 21,0 vagens.planta $^{-1}$. Resultados superiores foram encontrados em Ramos Júnior et al. (2005) ao avaliar o comportamento de cultivares de feijão, identificando-se aqueles superiores quanto aos componentes da produção verificaram média de 18,4 vagens.planta $^{-1}$. Stähelin et al. (2010) ao avaliar, identificar e selecionar genótipos de feijão pertencentes ao Banco Ativo de Germoplasma de Feijão, presente no estado de Santa Catarina, verificaram 25,1 vagens.planta $^{-1}$.

Testando dezenove cultivares de feijão comum para o sistema de produção orgânico obtiveram médias de 9 e 12 vagens.planta ${ }^{-1}$ em meio irrigado e sequeiro, respectivamente (CARVALHO; WANDERLEY, 2007). Guimarães et al. (2011) encontraram resultados médios expressos na ordem de 10,6 vagens.planta ${ }^{-1}$. O número vagens.planta ${ }^{-1}$ foi de 16,23 sendo esta variável influenciada pela pelo hábito de crescimento (MORAES et al., 2011). 
Tabela 4. Número de vagens.planta ${ }^{-1}$ (NVP) e matéria fresca da vagem com grãos (MFVG), de genótipos de feijãocomum nas condições do município de Areia. CCA- UFPB, 2013

\begin{tabular}{ccc}
\hline Genótipos & NVP (unid) & MFVG $(\mathrm{g})$ \\
\hline G1 & $8,31 \mathrm{a}$ & $3,96 \mathrm{~d}$ \\
G2 & $5,02 \mathrm{a}$ & $5,47 \mathrm{a}$ \\
G3 & $6,81 \mathrm{a}$ & $4,68 \mathrm{~b}$ \\
G4 & $5,85 \mathrm{a}$ & $4,37 \mathrm{c}$ \\
G5 & $5,50 \mathrm{a}$ & $4,37 \mathrm{c}$ \\
G6 & $6,81 \mathrm{a}$ & $3,41 \mathrm{~d}$ \\
G7 & $6,19 \mathrm{a}$ & $3,77 \mathrm{~d}$ \\
G8 & $5,54 \mathrm{a}$ & $5,36 \mathrm{a}$ \\
G9 & $5,29 \mathrm{a}$ & $4,66 \mathrm{~b}$ \\
G10 & $6,50 \mathrm{a}$ & $5,21 \mathrm{a}$ \\
G11 & $6,17 \mathrm{a}$ & $3,89 \mathrm{~d}$ \\
G12 & $5,67 \mathrm{a}$ & $4,89 \mathrm{~b}$ \\
G13 & $6,25 \mathrm{a}$ & $4,48 \mathrm{c}$ \\
G14 & $6,81 \mathrm{a}$ & $3,39 \mathrm{~d}$ \\
G15 & $5,81 \mathrm{a}$ & $4,22 \mathrm{c}$ \\
\hline Média & 6,17 & 4,41
\end{tabular}

Médias seguidas pela mesma letra, na coluna, não diferem estatisticamente entre si, pelo teste de Scott- Knott, a $5 \%$ de probabilidade.

Avaliando a matéria fresca da vagem com grão (MFVG) verificou-se que os genótipos G2, G8 e G10 apresentaram as maiores médias com valores médios de 5,47, 5,36 e 5,21 g, respectivamente. Esta variável torna-se importante, uma vez que no mercado a cultura do feijão pode ser comercializada fresca sem debulha, com os grãos ainda na vagem.

De acordo com Zilio et al. (2011), dentre os componentes do rendimento o maior número de vagens por planta, número de grãos por vagem e número de lóculos por vagem do feijoeiro contribuíram mais eficientemente na identificação dos genótipos mais promissores para rendimento de grãos. Segundo Guimarães et al. (2011) o número de vagens.planta ${ }^{-1}$ é o componente agronômico mais sensível ao estado hídrico do feijoeiro comum.

Tabela 5. Comprimento de vagem (CV), diâmetro de vagem (DV) e número de grãos.vagem ${ }^{-1}(\mathrm{NGV})$, de genótipos de feijãocomum nas condições do município de Areia. CCA-UFPB, 2013 


\begin{tabular}{|c|c|c|c|}
\hline Genótipos & $\mathrm{CV}(\mathrm{cm})$ & $\mathrm{DV}(\mathrm{cm})$ & NGV (unid) \\
\hline G1 & $9,49 \mathrm{a}$ & $0,75 \mathrm{~b}$ & $5,87 \mathrm{a}$ \\
\hline G2 & $10,44 \mathrm{a}$ & $0,90 \mathrm{a}$ & $4,35 \mathrm{c}$ \\
\hline G3 & $8,70 \mathrm{~b}$ & $0,83 \mathrm{~b}$ & $4,56 \mathrm{c}$ \\
\hline G4 & $8,20 \mathrm{~b}$ & $0,80 \mathrm{~b}$ & $4,29 \mathrm{c}$ \\
\hline G5 & $8,66 \mathrm{~b}$ & $0,78 \mathrm{~b}$ & $4,31 \mathrm{c}$ \\
\hline G6 & $7,62 \mathrm{~b}$ & $0,77 \mathrm{~b}$ & $4,47 \mathrm{c}$ \\
\hline G7 & $8,09 \mathrm{~b}$ & $0,75 \mathrm{~b}$ & $5,23 \mathrm{~b}$ \\
\hline G8 & $10,44 \mathrm{a}$ & $0,77 \mathrm{~b}$ & $4,46 \mathrm{c}$ \\
\hline G9 & $9,95 \mathrm{a}$ & $0,95 \mathrm{a}$ & $3,75 \mathrm{c}$ \\
\hline G10 & $10,16 \mathrm{a}$ & $0,78 \mathrm{~b}$ & $4,64 \mathrm{c}$ \\
\hline G11 & $9,12 \mathrm{~b}$ & $0,74 \mathrm{~b}$ & $5,98 \mathrm{a}$ \\
\hline G12 & $10,57 \mathrm{a}$ & $0,78 \mathrm{~b}$ & $4,43 \mathrm{c}$ \\
\hline G13 & $7,98 \mathrm{~b}$ & $0,79 \mathrm{~b}$ & $4,56 \mathrm{c}$ \\
\hline G14 & $9,00 \mathrm{~b}$ & $0,73 \mathrm{~b}$ & $6,27 \mathrm{a}$ \\
\hline G15 & $9,31 \mathrm{a}$ & $0,76 \mathrm{~b}$ & $5,50 \mathrm{~b}$ \\
\hline Média & 9,18 & 0,79 & 4,84 \\
\hline
\end{tabular}

$\overline{\text { Médias seguidas pela mesma letra, na coluna, não diferem estatisticamente entre si, pelo teste de }}$ Scott- Knott, a 5\% de probabilidade.

Para a variável comprimento de vagem $(\mathrm{CV})$ os maiores valores absolutos foram verificados nos genótipos G1 (9,49 g), G2 (10,44 g), G8 (10,44 g), G9 (9,95 g), G10 (10,16 g), G12 (10,57 g) e G15 (9,31 g). Resultados análogos foram verificados em Rigon et al. (2011) ao diagnosticarem comprimento de vagens com 10,11 cm.

$\mathrm{Na}$ variável número de grãos.vagem ${ }^{-1}(\mathrm{NGV})$ os genótipos G1, G11 e G14 apresentaram resultados integrais quando relacionado aos demais cultivares com valores que divergiram entre 5,23 a 6,27. Resultado similar foi encontrado por Rigon et al. (2011) com 5,35 grãos.vagem ${ }^{-1}$, ao determinar influências de espécies de culturas antecessoras sobre os índices agronômicos do feijãocomum. Assim também como em Zilio et al. (2011), ao observarem dados que diversificaram próximos de 5 a 6 sementes.vagem ${ }^{-1}$. Ramos Júnior et al. (2005) verificaram média de 5,3 grãos.vagem ${ }^{-1}$. Stähelin et al. (2010) averiguaram valores 5,4 a 2,7 grãos.vagem ${ }^{-1}$. Em cultivo irrigado 4,1 e sequeiro 4,2 grãos.vagem ${ }^{-1}$, foram verificados por (CARVALHO; WANDERLEY, 2007). Guimarães et al. (2011) avaliando 4 grupos de feijão comum designaram valores médios correspondentes a 5,6 grãos.vagem ${ }^{-1}$. 
Moraes et al. (2011) verificou o número médio de grãos.vagem ${ }^{-1}$ equivalente a 3,57.

Ramos Júnior et al. (2005) comentam que a massa de cem grãos e o número de grãos por vagem são os componentes de maior influência na produtividade de grãos de cultivares de feijão.

Tabela 6. Matéria fresca de cemgrãos (MFCG), matéria seca de cem grãos (MSCG) e índice de palha (IP), de genótipos de feijão comum nas condições do município de Areia. CCA-UFPB, 2013

\begin{tabular}{cccc}
\hline Genótipos & MFCG & MSCG & IP \\
\hline G1 & $30,72 \mathrm{c}$ & $16,19 \mathrm{f}$ & $0,45 \mathrm{a}$ \\
G2 & $61,14 \mathrm{a}$ & $30,87 \mathrm{a}$ & $0,48 \mathrm{a}$ \\
G3 & $32,56 \mathrm{c}$ & $23,06 \mathrm{~d}$ & $0,32 \mathrm{~b}$ \\
G4 & $51,12 \mathrm{~b}$ & $23,33 \mathrm{~d}$ & $0,50 \mathrm{a}$ \\
G5 & $50,29 \mathrm{~b}$ & $26,72 \mathrm{~b}$ & $0,49 \mathrm{a}$ \\
G6 & $36,40 \mathrm{c}$ & $20,83 \mathrm{e}$ & $0,47 \mathrm{a}$ \\
G7 & $32,77 \mathrm{c}$ & $18,83 \mathrm{e}$ & $0,45 \mathrm{a}$ \\
G8 & $57,28 \mathrm{a}$ & $27,86 \mathrm{~b}$ & $0,48 \mathrm{a}$ \\
G9 & $51,58 \mathrm{~b}$ & $25,63 \mathrm{c}$ & $0,41 \mathrm{a}$ \\
G10 & $56,13 \mathrm{a}$ & $25,07 \mathrm{c}$ & $0,50 \mathrm{a}$ \\
G11 & $30,89 \mathrm{c}$ & $16,85 \mathrm{f}$ & $0,47 \mathrm{a}$ \\
G12 & $57,60 \mathrm{a}$ & $27,42 \mathrm{~b}$ & $0,53 \mathrm{a}$ \\
G13 & $49,23 \mathrm{~b}$ & $25,24 \mathrm{c}$ & $0,50 \mathrm{a}$ \\
G14 & $25,66 \mathrm{~d}$ & $13,84 \mathrm{~g}$ & $0,47 \mathrm{a}$ \\
G15 & $24,99 \mathrm{~d}$ & $16,78 \mathrm{f}$ & $0,32 \mathrm{~b}$ \\
\hline Média & 43,22 & 22,57 & 0,46
\end{tabular}

Médias seguidas pela mesma letra, na coluna, não diferem estatisticamente entre si, pelo teste de Scott- Knott, a $5 \%$ de probabilidade.

Para a característica matéria fresca de cem grãos (MFCG) verificou-se que o genótipo G2 tendenciou ao maior valor médio absoluto com $61,14 \mathrm{~g}$, no entanto, não diferiram estatisticamente dos genótipos G8 (57,28 g), G10 (56,13 g) e G12 (57,60 g). As menores médias foram representadas nos genótipos G14 (25,66 g) e G15 (24,99 g).

O genótipo G2 apresentou a maior média para o caráter matéria seca de cem grãos (MSCG) com 30,87 g. Rigon et al. (2011) objetivando determinar as influências das espécies de culturas antecessoras sobre os atributos agronômicos do feijão averiguaram que o peso 
seco de cem sementes variou de 13,25 a 16,95 g. Zilio et al. (2011) objetivando verificar a contribuição relativa dos componentes do rendimento para a produção final em genótipos crioulos de feijão, cultivados em três ambientes, comprovaram médias semelhantes com valores máximos de 31,9 e mínima de 28,3 g. Ramos Júnior et al. (2005) observaram média de 27,9 para o peso seco de cem sementes. Coelho et al. (2010) caracterizando o potencial fisiológico da semente de feijão de genótipos crioulos observaram que o peso médio de cem sementes variaram de 15,21 a 64,68 g. Soares Júnior (2012) trabalhando com seis cultivares crioulas verificaram que o peso seco de cem sementes variou de 34,36 a 15,74 g. Carvalho e Wanderley (2007) observaram médias que variaram de 33,4 e 24,9 g em sistema irrigado e sequeiro, respectivamente. Guimarães et al. (2011) observaram números médios equivalente a 22, 71 g. Moraes et al. (2011) não verificaram diferença estatística entre as cultivares, apresentando média de 24,83 g. Para Carvalho e Wanderley (2007) o aumento do número de vagens e do número de grãos por vagem tem como consequência à diminuição do peso de cem grãos.

O caractere índice de palha (IP), diz exatamente qual o equivalente peso de grãos adquirido na comercialização das vagens frescas, uma vez que apenas os grãos é o componente alimentar humano, ressalvando-se que o resíduo pode destinasse a alimentação de animais domésticos. De modo geral verificou-se que os genótipos não diferiram entre si, com exceção para o G3 e G15, onde ambos apresentaram índice media equivalente a $(0,32)$. Esses dados informam que $1 \mathrm{~kg}$ de vagens intactas do genótipo G12 corresponde a 0,53 kg de grãos, ao passo que $1 \mathrm{~kg}$ do G15 condiz a 0,32 kg de grãos propriamente dito.

Tabela 7. Produtividade de grãos (PG), perdas de produção $(\mathrm{PP})$ e rendimento de grãos (RG), de genótipos de feijão comum nas condições do município de Areia. CCA-UFPB, 2013

\begin{tabular}{|c|c|c|c|}
\hline & PG & $\mathrm{PP}$ & $\mathrm{RG}$ \\
\hline Genótipos & ----------------- & 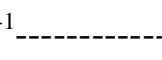 & ---- \\
\hline G1 & $581,75 \mathrm{~b}$ & $81,98 \mathrm{~b}$ & $\overline{485,03 \mathrm{~b}}$ \\
\hline G2 & $513,43 \mathrm{~b}$ & $107,63 \mathrm{a}$ & $346,53 \mathrm{c}$ \\
\hline G3 & $614,42 \mathrm{~b}$ & $99,58 \mathrm{~b}$ & $516,75 \mathrm{~b}$ \\
\hline G4 & $552,87 \mathrm{~b}$ & $78,20 \mathrm{~b}$ & $380,59 c$ \\
\hline G5 & $523,73 \mathrm{~b}$ & $81,66 \mathrm{~b}$ & $484,26 \mathrm{~b}$ \\
\hline G6 & $502,55 \mathrm{~b}$ & $148,42 \mathrm{a}$ & $354,13 \mathrm{c}$ \\
\hline G7 & 806,7 a & $81,87 \mathrm{~b}$ & $703,4 \mathrm{a}$ \\
\hline G8 & $731,55 \mathrm{a}$ & $81,09 \mathrm{~b}$ & $641,34 \mathrm{a}$ \\
\hline
\end{tabular}




\begin{tabular}{clcr} 
G9 & $494,57 \mathrm{~b}$ & $51,61 \mathrm{~b}$ & $430,88 \mathrm{c}$ \\
G10 & $776,2 \mathrm{a}$ & $108,32 \mathrm{a}$ & $707,82 \mathrm{a}$ \\
$\mathrm{G} 11$ & $545,24 \mathrm{~b}$ & $147,00 \mathrm{a}$ & $376,09 \mathrm{c}$ \\
$\mathrm{G} 12$ & $648,5 \mathrm{a}$ & $143,01 \mathrm{a}$ & $492,59 \mathrm{~b}$ \\
$\mathrm{G} 13$ & $609,85 \mathrm{~b}$ & $80,45 \mathrm{~b}$ & $527,9 \mathrm{~b}$ \\
$\mathrm{G} 14$ & $545,32 \mathrm{~b}$ & $36,99 \mathrm{~b}$ & $505,32 \mathrm{~b}$ \\
G15 & $701,61 \mathrm{a}$ & $73,54 \mathrm{~b}$ & $615,31 \mathrm{a}$ \\
\hline Média & 611,89 & 93,42 & 504,53
\end{tabular}

Médias seguidas pela mesma letra, na coluna, não diferem estatisticamente entre si, pelo teste de Scott- Knott, a 5\% de probabilidade.

$\mathrm{Na}$ variável produtividade de grãos (PG) foi possível diagnosticar diferença significativa entre os genótipos, onde de forma absoluta a menor média foi constatada nos genótipos G7 (806,70 kg.ha $\left.{ }^{-1}\right)$, G8 (731,55 kg.ha $\left.{ }^{-1}\right)$, G10 (776,60 kg.ha $\left.{ }^{-1}\right)$, G12 (648,5 kg.ha $\left.{ }^{-1}\right)$ e G15 (701,61 kg.ha $\left.{ }^{-1}\right)$. Resultado inferior foi verificado em Zilio et al. (2011) que ao estudarem cultivares crioulas verificaram médias de produtividade que variaram de 493,3 a 5096,1 kg.ha ${ }^{-1}$. Resultados também elevados foram datados por Ramos Júnior et al. (2005), ao observarem média de 3046 kg.ha ${ }^{-1}$. Assim também como em Stähelin et al. (2010) ao constatarem média máxima de 4791,5 e mínima de 621 kg.ha ${ }^{-1}$. Guimarães et al. (2011) estudando a adaptação de quarenta e nove genótipos de feijoeiro comum, observaram média de produtividade na importância de $2084 \mathrm{~kg} \cdot \mathrm{ha}^{-1}$.

De forma unânime os genótipos G9 (51,61 kg.ha- $\left.{ }^{-1}\right)$ e G14 (36,99 kg.ha' $)$ apresentaram as menores perdas de produção (PP), ao passo que os genótipos G6 (148,42 kg.ha $\left.{ }^{-1}\right)$, G11 $\left(147,00 \mathrm{~kg} \cdot \mathrm{ha}^{-1}\right)$ e $\mathrm{G} 12\left(143,01 \mathrm{~kg} \cdot \mathrm{ha}^{-1}\right)$, alegaram as maiores médias de perdas.

Quanto aos índices de rendimento de grãos $(\mathrm{RG})$ as maiores médias foram observadas nos genótipos G7, G8, G10 e G15 com valores de 703,40, 641,34, 707,82 e 615,31 kg.ha ${ }^{-1}$. Resultado superior foi diagnosticado em Rigon et al. (2011) ao verificarem rendimentos superiores a 1200 kg.ha ${ }^{-1}$; e em Carvalho e Wanderley (2007) com média de 2263 kg.ha ${ }^{-1}$, em sistema irrigado e $2155 \mathrm{~kg} \cdot \mathrm{ha}^{-1} \mathrm{em}$ sistema de sequeiro, após avaliação de cultivares de feijão comum para o plantio em sistema orgânico no cerrado. Moraes et al. (2011) avaliando o desempenho produtivo de cultivares de feijoeiro, obtiveram rendimento médio de grãos de $891,58 \mathrm{~kg} \cdot \mathrm{ha}^{-1}$.

\section{CONCLUSÕES}


O maior número de grãos por vagem foi obtido nos genótipos G1, G11 e G14; o genótipo G2 apresentou maior acumulo de biomassa nos grãos; os genótipos G7, G8, e G15 apresentaram as maiores médias de produtividade e rendimento, além de menor perda de produção.

\section{REFERÊNCIAS}

ASSIS, R.L. Agricultura Orgânica e Agroecologia: questões conceituais e processo de conversão. EMBRAPA Agrobiologia, 2005. 35p. (Documentos, 196).

BARROSO, A.A.M.; YAMAUTI, M.S.; ALVES, P.L.C.A. Interferência entre espécies de planta daninha e duas cultivares de feijoeiro em duas épocas de semeadura. Bragantia, Campinas, v. 69, n. 3, p. 609-616, 2010.

BENINCASA, M.M.P. Análise de Crescimento de Plantas (noções básicas). Jaboticabal. FUNEP. 2004. 42 p.

CABRAL, P.D.S.; SOARES, T.C.B.; LIMA, A.B.P.; SOARES, Y.J.B.; SILVA, J.A. Análise de trilha do rendimento de grãos de feijoeiro (Phaseolus vulgaris L.) e seus componentes. Revista Ciência Agronômica, Fortaleza, v. 42, n. 1, p. 132-138, 2011.

CARVAlHO, M.A.C.; SORATTO, R.P.; ALVES, M.C.; ARF, O.; SÁ, M.E. Plantas de cobertura, sucessão de culturas e manejo do solo em feijoeiro. Bragantia, Campinas, v. 66, n. 4, p. 659-668, 2007.

CARVALHO, W.P.; WANDERLEY, A.L. Avaliação de cultivares de feijão comum para o plantio em sistema orgânico no Cerrado, ciclo 2004/2005. Bioscience Journal, Uberlândia, v. 23, n. 3, p. 50-59, 2007.

COELHO, C.M.M.; MOTA, M.R.; SOUZA, C.A.; MIQUELLUTI, D.J. Potencial fisiológico em sementes de cultivares de feijão crioulo (Phaseolus vulgaris L.). Revista Brasileira de Sementes, Londrina, v. 32, n. 3, p. 97-105, 2010.

ELIAS, H.T.; VIDIGAL, M.C.G.; GONELA, A.; VOGT, G.A. Variabilidade genética em germoplasma tradicional de feijão-preto em Santa Catarina. Pesquisa Agropecuária Brasileira, Brasília, v. 42, n. 10, p. 1443-1449, 2007. 
EMBRAPA. Manual de métodos de análise de solo. Rio de Janeiro, Centro Nacional de Pesquisa de Solos. EMBRAPA. 1997. 212 p.

EMBRAPA. Sistema brasileiro de classificação de solo. Brasília: EMBRAPA, 1999. 412p.

EMBRAPA.

2003.

Disponível

em:

https://www.agencia.cnptia.embrapa.br/recursos/circ_60ID-cRtyuL7Uwc.pdf. Acesso em: 10 fev. 2019.

FERREIRA, D.F. Manual do sistema SISVAR para análises estatísticas. Lavras: UFV, 2000. 66 p.

FINATTO, R.A.; SALAMONI, G. Agricultura familiar e agroecologia: perfil da produção de base agroecológica do município de Pelotas/RS. Sociedade e Natureza, Uberlândia, v. 20, n. 2, p. 199-217, 2008.

GALBIATTI, J.A.; SILVA, F.G.; FRANCO, C.F.; CARAMELO, A.D. Desenvolvimento do feijoeiro sob o uso de biofertilizante e adubação mineral. Engenharia Agrícola, Jaboticabal, v. 31, n. 1, p. 167-177, 2011.

GONÇALVES, J.G.R.; CHIORATO, A.F.; MORAIS, L.K.; PERINA, E.F.; FARIAS, F.L.; CARBONELL, S.A.M. Estudo da estabilidade fenotípica de feijoeiro com grãos especiais. Ciência agrotecnológica, Lavras, v. 34, n. 4, p. 922-931, 2010.

GONDIM, A.W.A. Geoeconomia e agricultura no Brejo Paraibano. João Pessoa: Editora Universitária. 1999. 209 p.

GUIMARÃES, C.M.; STONE, L.F.; PELOSO, M.J.D.; OLIVEIRA, J.P. Genótipos de feijoeiro comum sob deficiência hídrica. Revista Brasileira de Engenharia Agrícola e Ambiental, v. 15, n. 7, p. 649-656, 2011.

IBGE (Instituto Brasileiro de Geografia e Estatística). Plataforma SIDRA-IBGE. Disponível em: http://www.sidra.ibge.gov.br/,. Acesso em: 27 abr. 2019. 
LIMA, G.C. O discurso da sustentabilidade e suas implicações para a educação. Ambiente e Sociedade, São Paulo, v. 6, n. 2, 2003.

LOPES, A.S.; OLIVEIRA, G.Q.; FILHO, S.N.S.; GOES, R.J.; CAMACHO, M.A. Manejo de irrigação e nitrogênio no feijoeiro comum cultivado em sistema plantio direto. Revista Ciência Agronômica, Fortaleza, v. 42, n. 1, p. 51-56, 2011.

MACÊDO, N.M.M.N.; CÂNDIDO, G.A. Índice de Desenvolvimento Sustentável Local e suas influências nas políticas públicas: um estudo exploratório no município de Alagoa Grande - PB. Gestão de Produção, São Carlos, v. 18, n. 3, p. 619-632, 2011.

MALUF, R.S. Mercados agroalimentares e a agricultura familiar no Brasil: agregação de valor, cadeias integradas e circuitos regionais. Ensaios FEE, Porto Alegre, v. 25, n. 1, p. 299322, 2004.

MASTRANTONIO, J.J.S.; PORTO, R.G.; GOMES, M.C. A escolha de cultivares de feijão através de um modelo multicritério baseado no saber local. Revista Brasileira de Agroecologia, Porto Alegre, v. 2, n. 1, p. 694-697, 2007.

MELO, L.C.; MELO, P.G.S.; FARIA; L.C., DIAZ, J.L.C.; PELOSO, M.J.D.; RAVA, C.A.; COSTA, J.G.C. Interação com ambientes e estabilidade de genótipos de feijoeiro-comum na Região Centro-Sul do Brasil. Pesquisa Agropecuária Brasileira, Brasília, v. 42, n. 5, p. 715 723, 2007.

MELO, R.M.S.; DUARTE, G.B. Impacto do Programa Bolsa Família sobre a Frequiência Escolar: o caso da agricultura familiar no Nordeste do Brasil. RESR, Piracicaba, SP, v. 48, n. 3, p. 635-656, 2010.

MORAES, M.T.; CHERUBIN, M.R.; SANTI, A.L.; SILVA, V.R. Potencial de rendimento de feijoeiro de diferentes hábitos na região norte do Rio Grande do Sul. Enciclopédia Biosfera - Centro Científico Conhecer, Goiânia, v. 7, n. 12, p. 1-10, 2011.

NEVES, M.C.P. Segurança na produção agrícola de alimentos. Seropédica: 
EMBRAPA Agrobiologia, Documentos, n. 223, 2006. 14p.

NEY, M.G.; HOFFMANN, R. Educação, concentração fundiária e desigualdade de rendimentos no meio rural brasileiro. RESR, Piracicaba, SP, v. 47, n. 1, p. 147-182, 2009.

PEREIRA, H.S.; MELO, L.C.; FARIA, L.C.; PELOSO, M.J.D.; COSTA, J.G.C.; RAVA, C.A.; WENDLAND, A. Adaptabilidade e estabilidade de genótipos de feijoeiro-comum com grãos tipo carioca na Região Central do Brasil. Pesquisa Agropecuária Brasileira, Brasília, v. 44, n. 1, p. 29-37, 2009.

PEREIRA, H.S.; MELO, L.C.; FARIA, L.C.; PELOSO, M.J.D.; DÍAZ, J.L.C.; WENDLAND, A. Indicação de cultivares de feijoeiro - comum baseada na avaliação conjunta de diferentes épocas de semeadura. Pesquisa Agropecuária Brasileira, Brasília, v. 45, n. 6, p. 571-578, 2010a.

PEREIRA, H.S.; MELO, L.C.; FARIA, L.C.; PELOSO, M.J.D.; WENDLAND, A. Estratificação ambiental na avaliação de genótipos de feijoeiro-comum tipo Carioca em Goiás e no Distrito Federal. Pesquisa Agropecuária Brasileira, Brasília, v. 45, n. 6, p. 554-562, $2010 b$.

RAMOS JUNIOR, E.U.; LEMOS, L.B.; SILVA, T.R.B. Componentes da produção, produtividade de grãos e características tecnológicas de cultivares de feijão. Bragantia, Campinas, v. 64, n. 1, p. 75-82, 2005.

RIBEIRO, N.D.; ANTUNES, I.F.; SOUZA, J.F.; POERSCHIV, N.L. Adaptação e estabilidade de produção de cultivares e linhagens-elite de feijão no Estado do Rio Grande do Sul. Revista Ciência Rural, Santa Maria, v. 38, n. 9, 2008.

RIGON, J.P.G.; BARONIO, C.A.; ZWIRTES, A.L.; CAPUANI, S. Sucessão de plantas de cobertura sobre os componentes de rendimento no feijoeiro. Revista Verde de Agroecologia e Desenvolvimento Sustentável, Mossoró, v. 6, n. 4, p. 196-203, 2011.

SALGADO, T.P.; SALLES, M.S.; MARTINS, J.V.F.; ALVES, P.L.C.A. Interferência das plantas daninhas no feijoeiro carioca. Planta Daninha, Viçosa, v. 25, n. 3, p. 443-448, 2007. 
SCHOLTEN, R.; PARREIRA, M.C.; ALVES, P.L.C.A. Período anterior à interferência das plantas daninhas para a cultivar de feijoeiro 'Rubi' em função do espaçamento e da densidade de semeadura. Acta Scientiarum Agronomy, Maringá, v. 33, n. 2, p. 313-320, 2011.

SILVA, C.A.; ABREU, A.F.B.; RAMALHO, M.A.P.; CARNEIRO, J.E.S. Implicações da origem das linhagens de feijoeiro na magnitude da interação com ambientes. Pesquisa Agropecuária Brasileira, Brasília, v. 46, n. 7, p. 720-728, 2011.

SILVEIRA, N.T.; SOUZA, E.B.; ALVES, C.X.; MARQUES, R.L.L.; ANTUNES, I.F. Variabilidade morfológica de sementes de Phaseolus vulgaris L. provenientes de coleta na região dos Litorais Médio e Sul do Rio Grande do Sul. In: Congresso de Iniciação Científica, 16., 2007, Pelotas, RS. Resumos... p. 4.

SOARES JÚNIOR, M.S.; CALIARI, M.; BASSINELLO, P.Z.; FERNANDES, P.M.; BECKER, F.S. Características físicas, químicas e sensoriais de feijões crioulos orgânicos, cultivados na região de Goiânia-GO. Revista Verde de Agroecologia e Desenvolvimento Sustentável, Mossoró, v. 7, n. 3, p. 109-118, 2012.

SOUZA, H.A.; NATALE, W.; ROZANE, D.E.; HERNANDES, A.; ROMUALDO, L.M. Calagem e adubação boratada na produção de feijoeiro. Revista Ciência Agronômica, Ceará, v. 42, n. 2, p. 249-257, 2011.

STÄHELIN, D.; GUIDOLIN, A.F.; COIMBRA, J.L.M.; VERISSIMO, M.A.A.; MORAIS, P.P.P.; ROCHA, F. Pré-melhoramento em feijão: perspectivas e utilização de germoplasma local no programa de melhoramento da UDESC. Revista de Ciências Agroveterinárias, Lages, v. 9, n. 2, p. 150-159, 2010.

TEIXEIRA, I.R.; SILVA, G.C.; TIMOSSI, P.S.; SILVA, A.G. Desempenho agronômico de cultivares de feijão-comum consorciado com mamona. Revista Caatinga, Mossoró, v. 24, n. 4, p.55-61, 2011.

TEIXEIRA, I.R.; SILVA, R.P.; SILVA, A.G.; FREITAS, R.S. Competição entre feijoeiros e plantas daninhas em função do tipo de crescimento dos cultivares. Planta Daninha, Viçosa, 
v. 27, n. 2, p. 235-240, 2009.

TORRES, S.B.; OLIVEIRA, F.N.; OLIVEIRA, R.C.; FERNANDES, J.B. Produtividade e morfologia de acessos de caupi, em Mossoró, RN. Horticultura Brasileira, Campinas, v. 26, n. 4, 2008.

ZILIO, M.; CILEIDE COELHO, C.M.M.; SOUZA, C.A.; SANTOS, J.C.P.; MIQUELLUTI, D.J. Contribuição dos componentes de rendimento na produtividade de genótipos crioulos de feijão (Phaseolus vulgaris L.). Revista Ciência Agronômica, Fortaleza, v. 42, n. 2, p. 429438, 2011. 